\title{
Dinámica de la subjetividad en la formación de profesores para la educación secundaria
}

\author{
José Luis Martínez Díaz \\ Rosa María Vallejo Camacho \\ María Isabel Vargas Calanda \\ Departamento de Posgrado de la Escuela Normal Superior del \\ Estado de México
}

\section{Resumen}

1 artículo aborda elementos con $\checkmark$ los cuales se pretende comprender la subjetividad que acompaña a la formación docente en una escuela normal superior. Esfuerzo que aproxima al conocimiento de experiencias significativas de alumnos normalistas, que en la mayoría de los casos, necesitan ser tomados en cuenta por quienes en la cotidianidad se ocupan en la formación inicial de docentes para la educación básica o quienes desean saber acerca de ello.

Palabras clave: experiencias significativas, intersubjetividad, formación inicial de docentes, mundo de la vida.

\section{La situación problemática que promueve la reflexión}

En la visión cotidiana de los formadores de docentes, se ha trabajado poco con respecto a la recuperación reflexiva de las experiencias adquiridas por los estudiantes. Acaso el interés respecto de su formación se concentra por lo regular en su asistencia, elaboración de planes de trabajo, puntualidad, presentación y cumplimiento con lo planeado. O en las características del documento recepcional con el que buscan titularse.

En el contexto de la cotidianidad en el que está inmersa la comunidad normalista, tan ocupada en la resolución de proyec- 
tos planeados de manera institucional y que exige la puntual realización de tareas ordinarias, se atiende poco lo relacionado conlas vivencias de los estudiantes fuera de las aulasy sus primeros acercamientos a las escuelas de práctica y la consecuente reflexión con los docentes formadores.

En este sentido vale la pena adentrarnos en la investigación reflexiva como posibilidad de recuperación de las vivencias más significativas en el proceso de formación inicial de los docentes, observando esa formación como un proceso de aprendizaje discontinuo, caracterizado por la periodización semestral en el que se diversifica la adquisición de conocimientos, habilidades, herramientas, valores, actitudes muy propios de cada periodo que puede ser analizado después de su culminación. De ahí el interés por buscar respuestas a interrogantes como las siguientes: ¿Qué cualidades tiene el aprendizaje docente, que bien podría ser concebido como un tipo más específico de aprendizaje, distinto al que se logra en la universidad o en las carreras tecnológicas? ¿cómo podría ser caracterizado y definido? ¿cómo se interpreta el estudiante a sí mismo, observándose desde el presente, y desde el lugar curricular que ocupa al final del octavo semestre? ¿cuáles son las experiencias más significativas que ha acumulado en la trayectoria de su formación profesional y quienes han incidido en su adquisición? En resumen, con la investigación reflexiva convendría saber ¿Cómo aprenden los alumnos de la escuela normal superior?

La idea hipotética general que subyace en el trabajo, consiste en que para poder entender el aprendizaje de la profesión docente por parte de los estudiantes de la Escuela Normal Superior del Estado de México (ENSEM) es importante analizar los conceptos, premisas y experiencias significativas, así como los rasgos y contenidos de esas experiencias que al reflexionarlas y expresarlas, brotan en cierto sentido, hacia la objetivación y luego se convierten en aspectos de observación e interpretación.

En la investigación se trabajó con un grupo de estudiantes normalistas de cuarto grado de licenciatura, cuyas experiencias directa o indirectamente pueden dar indicios de su desarrollo profesional y que también aporta elementos que quizá pueden fortalecer las expectativas pedagógicas de los formadores de docentes.

El artículo es producto de una línea de investigación educativa que inició en 2010 y se ha mantenido hasta el presente año. Desde hace cinco años la investigación ha privilegiado el análisis comprensivo y la búsqueda del significado subjetivo por lo que se ha optado por un estudio desde la perspectiva fenomenológica que se basa en las aportaciones deAlfred Schutz (1974, 1993 y 1995), Peter Berger y Thomas Luckmann (1998) entre otros autores. El estudio se enfoca al sí mismo de los estudiantes de licenciatura en educación secundaria en la especialidad de matemáticas. Para lograrlo, esta especie de análisis del Yo del otro, en términos de lo que sugiere Ricoeur (1996), tuvo que ser ubicada en el contexto de la trayectoria de la formación profesional del estudiante normalista. Trayectoria que está sintetizada en lo que se conoce como profesionalización, que es al mismo tiempo el 
núcleo de la línea de investigación que se instaura y que se abre para ulteriores investigaciones educativas.

Hemos encontrado en la investigación educativa el arte de reflexionar e intervenir lo que en la práctica se lleva a cabo, sea de manera directa o de modo indirecto a través de las actividades de los estudiantes de cuya formación somos responsables, en este sentido fue determinante la formación académica adquirida bajo la tutela de la Doctora en Pedagogía, Libertad Menéndez Menéndez (qepd), Investigadora nacional del Colegio de Pedagogía en la UNAM.

Hasta la fecha seguimos centrando la atención en el debate epistemológico que sostienen desde su aparición las disciplinas sociales, respecto de los métodos que siguen para investigar sus objetos y en el férreo y sistemático esfuerzo por sostener y argumentar su propio estatus científico. Asimismo, el subíndice conceptual de las ciencias sociales es un referente lingüístico que coordina los propósitos cognoscitivos en un gran plexo disciplinario caracterizado por el fluir interminable, pero riguroso, de conceptos especializados, términos y palabras que atraviesan y diluyen las fronteras disciplinarias en materia de educación.

Desde entonces quedó abierto, no sin dificultades de toda índole, el camino a la conciencia reflexiva, que siempre ha matizado la búsqueda por confirmarle a la pedagogía su propio status disciplinario, sin separarla de manera tajante y radical de las demás disciplinas que se ocupan también de interpretar las construcciones humanas, los objetos sociales y culturales, como lo es, y ha sido, la educación.
La permanencia de la educación en la Acción Social parece cifrarse en la esperanza por el acceso a mejores niveles de vida a través del conocimiento o de difundir todavía con cierto éxito, el modelo de vida o de organización política o económica que ha prevalecido. Su permanencia se fortalece a pesar de la influencia de otros factores de socialización de la cultura, como es el caso de internet, los medios masivos de comunicación y las herramientas de comunicación digital de moda en la actual sociedad del conocimiento.

Desde hace un buen número de años, los problemas aumentan o son cada vez más complejos en materia de educación. Como consecuencia de todo esto, parece sistematizarse la crítica hacia el sistema educativo. Esta crítica se dimensiona en un ambiente cada vez más difícil para los principales actores educativos, docentes y alumnos.

Aquí entendemos que la educación es inherente a la Acción Social, esto es, a la búsqueda de la vida y la permanencia siempre evolutiva de la sociedad, por ende es racional, intencional, sistemática e interesada en el logro de algún fin explícito o no. Enraizada en un proceso histórico social y cultural, la educación se matiza por las circunstancias y condiciones sociales materiales e ideológicas con las que coexiste. De esta situación la escuela nunca se salva, porque es la institución social a la que se le atribuye la responsabilidad de llevar a cabo la tarea educativa.

Sobre esta base también sostenemos que la educación necesita ser comprendida en el marco de todas y cada una de las circunstancias y condiciones objetivas de la socie- 
dad donde se realiza y que le permite responder de alguna manera a las expectativas generales que se plantean. En la escuela se da forma al modo o al estilo con que tanto maestros como alumnos construyen e interpretan la cultura, el conocimiento y la historia, incluso las formas de interacción social más elementales que ayudan a comprender las formas de interacción social más complejas.

Hoy en día, siguen sin agotarse los esfuerzos por analizar la educación desde el punto de vista reflexivo de los sujetos que desarrollan su trabajo en las aulas, tomándolos no como fuentes de datos comprobatorios de hechos sociales o pedagógicos concretos, sino de información significativa para reconstruir el mundo de su realidad cotidiana, es decir, lo que pasa en las aulas y en el entorno de su vida cotidiana. También, hoy en día se fortalece el imperativo de considerar la perspectiva de docentes y alumnos como actores fundamentales de la educación. Puesto que ellos son, quienes directa y cotidianamente construyen la educación como realidad vinculada estructuralmente a otras realidades como la economía y la política, que aunque diferentes, le son substancialmente importantes.

$\mathrm{Al}$ reconocer su valor como actores principales, es menester escucharles desde una propuesta altamente reflexiva, que al detonarla con método facilita el camino a la comprensión de los aspectos más íntimos y anónimos de la educación como lo que sucede en las aulas entre los profesores y los estudiantes; los modos en que se perciben unos a otros; los modos en los que los profesores se definen y se perciben a sí mismos, incluyendo la percepción de lo que hacen (educación) y de la institución donde la llevan a la práctica (la escuela).

\section{La reflexión como herramienta epistemológica}

La reflexión sobre la práctica docente, es acción de quienes quieren intencionalmente intervenir de manera sistemática, en el mundo de la vida donde están situados y mismo en el que desarrollan con diligencia y sobrada exquisitez ética y estética. La reflexión también es acción de quienes aspiran a detenerse algunos momentos para pensar-se a sí mismos, pensar las prácticas cotidianas propias y los sistemas de relación que han establecido con sujetos sociales semejantes a ellos; inclusive pensar las consecuencias que producen con cada una o todas las acciones y/o relaciones llevadas a efecto o establecidas, para ellos y sus contemporáneos.

La necesidad de la reflexión se dimensiona como necesidad en el contexto de un mundo donde al parecer, nos hemos acostumbrado a escuchar decir que hay más interpretaciones que hechos. Aquí, podemos vislumbrar junto con el filósofo Maurizio Ferrari (2011) precisamente lo opuesto, que hay una gran cantidad de hechos y sólo algunas lecturas de ellos, en esa lectura, participa de manera dinámica la práctica reflexiva.

Empero es importante vislumbrar el riesgo que conlleva el ejercicio del solo pensar el sí-mismo en la cotidianidad como contemplación. Actividad que tarde o temprano podría conducir a quien reflexiona a la mera simulación y a la frus- 
tración de nunca encontrar respuesta a las interrogantes planteadas o al verse impedido para la transformación de la situación detectada.

La práctica reflexiva capacita a los agentes para actuar deliberada e intencionalmente para conseguir objetivos futuros y para otorgar algún sentido lógico a las actividades que cotidianamente se desarrollan o a los productos que se generan, aprovechando fundamentalmente los saberes comunitarios construidos. Y si bien la capacidad del pensar reflexivo puede liberar del sometimiento a las actividades cotidianas o rutinarias, también ofrece la ocasión y la posibilidad de vislumbrar el error y el fracaso. Situación de la que se priva quien solo obedece a la dinámica de sus hábitos o a sus costumbres ya sedimentadas.

En las humanidades y en las disciplinas sociales, los términos práctica y acción se refieren al conjunto peculiar de actividades racionales e intencionales que el ser humano, visto también como actor o sujeto social, proyecta y lleva a cabo para resolver sus necesidades y con esas actividades de por medio, establece todo tipo de relaciones e interacciones con sus semejantes, produciendo objetos culturales, es decir, herramientas e instituciones sociales de todo tipo que quedan como evidencia empírica de la dinámica intersubjetiva que les ha precedido.

La educación es acción social, histórica, cultural y estéticamente fundada, que juega un papel decisivo para la formación, no de individuos aislados, sino de la especie humana que se manifiesta en cada sujeto que es educado. ¿Cuál es la sustancia, el elemento, la materia con la que se trabaja en educación? La respuesta tal vez nunca sea clara ni definitiva, ni tendría porque serlo, además. Identificar cuál es aquello con lo que se trabaja en educación, ayudaría a resolver otra pregunta, ¿para que se trabaja en esa dimensión?

Ambas preguntas han permanecido en el pensamiento de quienes hacen de la educación una profesión y dedican a ella buena parte de su vida, estudiándola o llevándola a la práctica. La educación, como trabajo socialmente reconocido, es decir, como trabajo regulado oficialmente normado por el Estado, es producto de dos grandes movimientos de transformación social política y económica: la revolución industrial y la revolución francesa, movimientos que transformaron la sociedad occidental desde mediados y hasta fines del siglo XVIII. Desde entonces, importa plantear cuestiones cuya búsqueda de respuestas ha trascendido los siglos posteriores. Hoy, sigue vigente plantearse interrogantes del tipo ¿qué es educar? ¿Para qué se educa? ¿A quién se educa? ¿Quién educa a quién? ¿Qué cualidades tendría que cumplir aquélla persona que se dedica profesionalmente a educar? Y dado que en cada época se produjeron respuestas, ¿cuáles serían las nuestras en el siglo $\mathrm{XXI}$ ?

En la nueva sociedad, inestable y terrible, inventiva e innovadora, el proyecto se superpone a la memoria; el futuro domina el pasado; los modelos son constantemente puestos en tela de juicio. El nuevo siglo, parece reclamar según Carneiro (2005) el rebrote de la educación como reflejo y pro- 
yecto de una cultura: arraigada en la memoria, pero también abierta al porvenir.

En este sentido y como los contenidos de la conciencia de un actor social adulto $y$ en estado de alerta, no son directamente accesibles al análisis del investigador educativo comprensivo, nos vimos obligados a organizar procesos dialógicos, en una relación cara a cara con el actor social. Esto se logró con base en un esquema de interrogación que sintetizó elementos de la historia de vida y la entrevista. Con estas herramientas, se tuvo acceso más o menos secuencial a ciertos aspectos de la vida ordinaria que han acompañado la profesionalización de los estudiantes normalistas, mismas que en conjunto integran para la óptica del actor como para el intérprete, el esquema de experiencias significativas que acompañan la formación.

La idea de entrevista a profundidad que fue construida mediante la investigación, quedó definida como

...el proceso comunicativo intencional, consciente, sistemático y cara a cara entre el investigador y uno o más informantes, con propósitos de atención, reflexión y expresión de contenidos de conciencia que, a manera de movimientos, gestos, palabras o juicios, son emitidos como respuesta a interrogantes planteadas por ese investigador con respecto a uno o varios temas, o asuntos particulares pasados, traídos a la corriente de conciencia de cada actor en el presente (Martínez, 2007: 25).

Con la entrevista, el investigador puede seguir paso a paso, por así decirlo, la acción de la persona que es objeto del análisis subjetivo en el transcurso del proceso de aten- ción a un esquema de significado motivado por la interrogación. De ese modo, el trabajo reflexivo con los estudiantes, esa relación cara a cara, en principio unilateral entre meros contemporáneos, paulatinamente devino en simultaneidad de las corrientes de conciencia, hasta lograr la constitución de un tipo de relación-nosotros-concreta, con la que se hace posible a través de un proceso organizado de interrogación, la reconstrucción politética de vivencias y sus orlas, de actividades, experiencias y acervo de conocimientos adquiridos en la significativa trayectoria que dibuja la historia pedagógica y social de 8 semestres transcurridos en la duración de la licenciatura en educación secundaria.

El trabajo con los informantes (19 alumnos de $4^{\circ}$ grado de licenciatura en educación secundaria) devino en recuperación de experiencias significativas que sólo pueden observarse desde Actos reflexivos en el sentido que señala Dewey (1998), como actos que implican registro de algo realizado, alguna visión del futuro y alguna anticipación o predicción. Actos con los cuales cada sujeto es capaz de manera voluntaria, de reconstruir no solamente su vivencia sino también su propio sentir de la vivencia. La autorreflexión es acontecimiento que sucede en el Aquí y el Ahora específicos, que hurga en el pasado, observándole de nueva cuenta con atención y con un estado de alerta, o "un plano de conciencia de elevadísima tensión, que se origina en una actitud plena de atención a la vida y sus requisitos"(Schutz, 1995).

La persona que ejerce dicha actitud, se haya plenamente interesada en la vida y en 
las actividades que desarrolla. De tal modo que se vivencia a sí misma en sus actos. Su atención se dirige casi exclusivamente a poner en práctica su proyecto, a ejecutar su plan ideado o preconcebido. Pero si con sus actos ejecutivos realiza sus planes, interactúa con Otros y organiza las diferentes perspectivas espaciales del mundo de la vida cotidiana donde está situada, con su atención a la vida esa persona puede recuperar los acontecimientos, recordándolos.

Como se aprecia, la autorreflexión guiada por la síntesis entre la historia de vida y la entrevista, aproximan al investigador a información relacionada con la circunstancia vital, social y cultural en voz de quien la narra, el sujeto social. Su diseño y aplicación exige plantear procesos sistemáticos de conversación intensa entre entrevistado y entrevistador, de encuentros únicos o discontinuos cara a cara entre el investigador y el informante. Para la construcción del guion se estudiaron los trabajos de especialistas como: Balán (1974), Magrassi (1979), Cicourel (1982), Schwartz y Jacobs (1984), Taylor y Bogdan (1986) Pujadas (1992), Corenstein y Medina (1997) quienes coinciden en sostener que con el empleo organizado de la historia de vida y la entrevista, el investigador puede acercarse al modo como los actores sociales observan, clasifican y experimentan su propio mundo. También coincidimos con Durán (2002) acerca de que la búsqueda del significado en la información puede llevarse a cabo mediante el proceso de codificación, que incluye la reunión y análisis de todos los datos que se refieren a temas, ideas, conceptos, interpretaciones y proposiciones.
Con la rememoración de algunos pasajes de su formación profesional, sobre todo en el parteaguas de su ingreso, es decir, los primeros semestres y de la situación que han experimentado en el $8^{\circ}$ semestre, cada uno de los estudiantes entrevistados pudo recuperar conscientemente las experiencias vívidas o más significativas que ha adquirido en su vida como estudiante. Aquí somos conscientes de que la reflexión es compleja dada la inmediatez de los procesos cognoscitivos desarrollados en cada etapa de su formación como estudiante, o porque es etapa de la formación en la que prevalecen, quizá, los intereses prácticos sobre los intereses reflexivos, de orden superior.

\section{La Escuela Normal Superior del Estado de México: realidad eminente que directamente se vivencia}

La investigación muestra, que el arribo de cualquier alumno a las instituciones de educación superior es indistinto. Su arribo puede obedecer a la determinación e influencia decisiva de los padres de familia, a la motivación despertada por la actuación de los profesores en edades tempranas o a una intencionalidad consciente del estudiante, dada su posición de adulto y con plena atención a la vida. Aspectos todos que junto con el acervo de conocimiento acumulado en sus experiencias anteriores, no sólo posibilita a cada estudiante elegir entre una u otra carrera o tomar las decisiones más adecuadas a sus idealizaciones, sino también a los maestros, acerca de que la opción por ellos elegida es precisamente la mejor. 
Es el caso, por ejemplo, de Adyae, Antonio y Berenice. Sujetos cuyas experiencias previas acerca de la Escuela Normal Superior difieren cualitativamente: Adyae (E01alnsjlm, p 6) explica que a la escuela normal superior “... había llegado desde dos años antes, cuando iba en la preparatoria, venimos aquí a un concurso de cómo se hace la ciencia."

Antonio (E06minslm, pp 4 y 5)por su parte refiere que llega a la normal superior “... después de haberme salido de la facultad de ingeniería. [...]Tenía pensado volver a regresar a la facultad de ingeniería. De hecho, cuando me dieron de baja tenía que esperarme dos años y medio para volver a inscribirme. Todavía faltaba un año completo exactamente cuando me di cuenta que ya no podía esperar más tiempo. Tenía que hacer algo porque no podía estar en mi casa toda la vida. Después de esos dos años, ¿qué pasaría si cuando quisiera entrar a la facultad de ingeniería de nuevo, no reunía los requisitos? Entonces dije, tengo que estudiar otra cosa, y fue cuando volvió a surgir la idea de entrar a un lugar donde me enseñaran matemáticas, pero también donde me pudiera servir para dar clases. Fue así como pedí informes en la escuela normal uno, pero ellos me mandaron a la normal superior. Era aquí donde se daba la licenciatura en matemáticas."

Y Berenice (E14adnslm, p. 8)afirma “... mi prima estudió en la generación anterior, y le pregunté si conocía la normal superior, me dijo que sí, que era la misma en la que estaba estudiando. Le pedí que cuando saliera la convocatoria me avisara. Y me avisó, vine y entregué la documentación necesaria. Además vine a los cursos propedéuticos, hice mi examen, pensé que no lo había pasado, pero, cuando nos dieron los resultados, observé que salió mi número de folio, me emocioné, me inscribí, entregué la documentación que me faltaba e inicié el ciclo escolar."

Las palabras de los estudiantes en cuestión parecen sugerir que la incertidumbre ocasionada por haber abandonado algún tipo de estudios; el conocimiento de otras personas respecto de la institución educativa en cuestión, como los familiares, los amigos; o intencionalidades propias ya definidas para optar por la carrera normalista, son entre otras, las diferentes vías para tener acceso al conocimiento más directo de la Escuela Normal Superior como institución educativa formadora de docentes. Ese conocimiento inicial les hace interpretar, en lo general, que se trata de una escuela que prepara a maestros de escuela secundaria.

No obstante, esa experiencia difiere cualitativamente de aquellas en que los estudiantes vivieron situaciones difíciles en otras instituciones educativas, los fracasos en otras carreras, los problemas enfrentados como estudiantes y el descubrimiento de la ENSEM como salida a sus propósitos de adquirir alguna formación profesional.

¿Qué es posible interpretar también en estas afirmaciones de acuerdo con la perspectiva teórica de análisis? Según se puede observar, las experiencias particulares en los respectivos horizontes de la vida social, han sido elementos que influyen decisivamente en la elección no solo de la carrera profesional, sino también de la institución 
educativa donde ese proyecto habría de llevarse a cabo. También se observa que el conocimiento de las experiencias de otros y hasta la propia crisis provocada por la serie de experiencias sedimentadas como alumnos de educación superior, marcan las idealizaciones que para el futuro han establecido los estudiantes entrevistados.

Aún más, ¿cómo es que el aspirante a ingresar a una institución de educación superior se da cuenta o se entera de la existencia de aquella y de las características que le presenta para ser seleccionada como la mejor opción? La investigación arroja información valiosa para darnos cuenta que el estudiante de educación superior no se mueve al azar, tampoco se deja llevar absolutamente por las circunstancias. Más bien es un sujeto que en su elección parece seguir un proceso irregular y discontinuo, hasta llegar al momento clave en su vida en el que se dispone a llevar a cabo la determinación para formarse, en este caso, como profesor, y de elegir en consecuencia, la institución educativa que mejor puede satisfacer esa aspiración.

Es el caso de Andrea (E03linslm, pp 5 y 6), para quien el arribo a la normal superior fue un largo proceso de "muchos tropiezos previos". Nos dice:

“... yo quería ser maestra (pero) no conocía las modalidades, porque en preparatoria no te dan mucha orientación. Decidí irme a la preparatoria de Santiago (Tianguistenco) ahí, las presiones de mis papás. Ellos decían que como iba a ser maestra de secundaria que yo podía dar más. Decidí ir a la universidad, primero fui a estudiar a la Pedagógica pero ahí el sistema no me gustó. También hice mi examen en la segunda ronda de la UAM para licenciado en matemáticas y me quedé. Saqué mis papeles de la UPN y me fui a la UAM. Pero en la universidad empezaron a darme más demostraciones, puras demostraciones y dije no, yo no quiero pasar el resto de mi vida dando demostraciones, esto no es para mí, o seguir investigando matemáticas verdaderas. Entonces dije ¡no!, yo no quiero hacer esto, quiero seguir estudiando para maestra. Luego, vengo a la normal superior. A ésta normal yo ya la conocía porque cuando iba en la preparatoria me comentaron mis maestros que porque no me venía a estudiar acá. En ese entonces dije que no. Pero, bueno, por esas razones llego aquí."

Desde el inicio Andrea quería ser maestra, pero las razones de sus padres se lo impidieron, y en ese proceso que siguió para encontrarse con la profesión hay lugar para reflexiones del tipo, "esto no es para mí"; también para la idealización de proyectos: "yo quería ser maestra". Inclusive, también hay lugar para tomar decisiones del tipo "yo no quiero pasar el resto de mi vida dando demostraciones, quiero seguir estudiando para maestra. Vengo a la normal superior."

Esas cosas que pueden parecer triviales son cruciales para el análisis subjetivo, porque permiten entender la forma en que los objetos sociales y culturales que el ser humano construye, como por ejemplo las instituciones educativas hasta cierto punto y durante un buen tiempo, permanecen fuera del conocimiento directo de muchos de los actores sociales. Por el contrario, el conocimiento que se tiene acerca de ellas, es un saber que proviene por vía indirecta, es decir, proviene de los medios de co- 
municación, los amigos, los familiares o los maestros.

La distribución social de la información, presenta a las instituciones educativas como ámbitos asequibles a la experiencia de cada quien o de todos los sujetos para quienes, presumiblemente, han sido socialmente constituidas. Inclusive, la falta de información suficiente sobre esas instituciones escolares y acerca de las características completas de las carreras que ofrecen, es un problema que enfrentan los estudiantes del caso y solo cuando las observan más de cerca, aprecian en toda su magnitud los propósitos de formación de cada una.

Paulatinamente, las instituciones educativas dejan de ser entidades anónimas para la conciencia del sujeto y entonces quedan al alcance no solo de su conocimiento, sino también de su experimentación sensible y subjetiva. En ese devenir de la experiencia cotidiana, el mundo y los objetos sociales que existen como nociones, ideas o imágenes confusas y vagas, se miran con mayor nitidez y sus dimensiones sociales son gradualmente más concretas, más reales, más objetivas.

Bajo estas consideraciones, el arribo de los estudiantes bajo estudio a la Escuela Normal Superior formalmente aparenta ser homogéneo, por cuanto que todos atraviesan por procesos de selección preestablecida. Empero, si se atiende a las particularidades recordadas, el arribo es heterogéneo y complejo, porque cada quien arriba con sus propias experiencias y expectativas a cuestas. Cada uno ha idealizado desde su horizonte biográfico la carrera profesional que desea cursar y con ese acervo de cono- cimiento a la mano, define la escuela y lo que espera para el día de mañana.

\subsection{El arribo a la ENSEM, la primera semana como estudiante}

La investigación facilitó cierta aproximación a las idealizaciones que los estudiantes entrevistados traen consigo tanto para el día de hoy, como para el día siguiente. Aquí la recuperación de sus recuerdos los inquieta. También, como entrevistador no atino a saber si la rememoración traerá evidencias gratas o desafortunadas. La subjetividad del estudiante aflora cuando decide por fin dar respuesta, arriesgándose, confiando en que su palabra no sea utilizada para otros fines, en su contra, por ejemplo. Sólo desea egresar, ya falta poco. Finalmente, los signos se hacen evidentes, hechos palabras, enunciados que solo se ven interrumpidos por titubeos o por reflexiones pausadas: Adyae (E01alnslm, p. 6) advierte "...Creí que esto iba a ser igual que en la facultad, [...] pero me costó adaptarme a la forma de trabajo de aquí, porque era totalmente diferente. Se trataba de imprimir mi opinión en un papel. [...] Yo buscaba y rebuscaba palabras, para que las cosas se oyeran bien y no tenía que ser así, sino que simplemente tenía que ser como yo lo creía. Lo entendí hasta la primera mitad del primer semestre."

A veces, el transitar de una institución a otra parece ser un asunto sin importancia, todo parece ser lo mismo. La inscripción en una institución educativa distinta a la que inicialmente se eligió, como por ejemplo, una facultad, "creí que iba a ser igual". Esperar cosas diferentes sería inusitado. No obstante, con el transcurrir de la formación 
se aprende a concebir la diferencia, cada estudiante entiende lo que tiene que hacer aquí y ahora: "imprimir mi opinión en un papel."

Las imágenes previas e iniciales del mundo social y cultural al que se arriba como estudiante poco a poco son actualizadas y/o transformadas. Un poco por la influencia de los contemporáneos con quienes se comparte cada horizonte. Otro tanto por las experiencias escolares que se van adquiriendo y con las cuales cada quien se acerca de manera diferencial a las pautas socioculturales institucionales que le permiten tipificar sujetos, procesos y objetos como: los maestros, las clases, los trabajos escolares, las formas de organización e interacción social con las cuales poco a poco se van familiarizando.

Rosa (E11sinslm, p. 6) por ejemplo, trae a cuentas la influencia decisiva de un profesor:

“... Me acuerdo mucho de un maestro que entró y se nos quedó viendo así, como viendo bichitos raros y yo dije, jay no!, va a empezar a decirnos cosas, a querer asustarnos. Pero, a la fecha, he entendido que si su actitud fue así no fue por querer asustarnos, sino por una razón, porque ya estamos en un nivel superior. ¿Sabes qué?, madura porque eres maestra, porque te vas a enfrentar a alumnos que están esperando algo de ti. Esa impresión que me dio fue de decir, estás en un nivel superior y debes madurar porque hay a quienes tu vas a formar ahora".

La anterior reflexión hace referencia a momentos donde el estudiante adopta actitudes similares a las que venía desarro- llando en escuelas anteriores, tal vez preparatorias. Su disposición hacia los procesos de formación no alcanza "la madurez" deseada por los profesores. No obstante, el retorno a la escuela secundaria es ahora diferente, regresan como profesores practicantes. El contacto con los alumnos de ese nivel educativo trae a cada informante las reminiscencias de una época, de un tiempo vivido no tan lejano, pero ahora, la escuela secundaria le exige seriedad a sus actitudes, a sus acciones. Los rasgos de personalidad de un maestro han comenzado a dibujarse.

Algo similar ocurre con Armando (E19adrnsm, p. 6)

“... Me encuentro [en la escuela normal] con maestros como Romero, muy exigente y muy bueno. Con él había mucho trabajo. Con él cambia nuestra forma de ver las cosas, como si todavía fuéramos en la preparatoria, donde dejaban trabajos y nada más lo que hacíamos era pasar del libro, pasarlo a la computadora e imprimirlo. En la normal nos encontramos con maestros que dicen, a ver, para mañana tráiganme este trabajo y nosotros queríamos hacer lo mismo que en la "prepa" y nos dicen aquí los maestros, esto lo copiaste de este libro, de esta página, esto lo dijo fulano de tal. Entonces nos quedamos sorprendidos y teníamos que leer, teníamos que entrarle a lo que es en verdad el trabajo. La escuela normal nos enseñó a redactar un texto, a hacer un ensayo, a hacer una crítica, nos enseñó muchísimo, nos enseñó hasta analizar un texto."

Los informantes en cuestión perciben que la situación escolar en la enseñanza superior es más compleja que en otros niveles. Más comprometida con lo que se quiere 
Ser y Hacer. Se dan cuenta que se comienza a ser profesionista desde el momento del ingreso a una institución de educación superior. Afirmaciones como "... madura porque ya eres maestra, porque te vas a enfrentar a alumnos que están esperando algo de ti," o "...teníamos que entrarle a lo que es en verdad el trabajo", son afirmaciones que provienen de una subjetividad consciente, con cierto dominio del Yo y del objeto al cual se le está otorgando atención durante la vida. Pero también, son afirmaciones que advierten ciertas concreciones en los esquemas iniciales de la formación docente.

En la escuela normal superior no existe pauta sociocultural y pedagógica que resuelva, en una dimensión diferente, el arribo, la consecuente orientación, y el desplazamiento pragmático del estudiante de nuevo ingreso por sus diferentes ámbitos o estratos. El estudiante incursiona solitario "lo entendí hasta que llegamos a la mitad del semestre"; "teníamos que entrarle al trabajo". No hay procesos de socialización del estudiante de nuevo ingreso. La adquisición de conocimientos acerca de la profesión es difícil y se ancla en los primeros momentos en el contraste de sentido: una cosa es la profesión idealizada, otra es la profesión que se construye con la superación de situaciones reales, adversas y obstáculos cotidianos.

El acervo de conocimiento del estudiante se transforma. El horizonte del mundo de la vida en el que puede ahora intervenir le plantea ciertos requisitos para poder operar. Ya no puede reproducir pautas escolares sedimentadas. El "así sucesivamente", ha sido interrumpido, ya no pue- de hacer lo mismo que realizaba en ciclos educativos anteriores. Las actividades, el rol pedagógico de "profesor practicante" y los procesos que desencadenan su organización y su ejecución, delimitan ahora su campo de acción.

\subsection{Las expectativas iniciales y los tres primeros semestres de la formación}

En el transcurrir de las primeras semanas en la escuela normal superior, la formación como docente le implica al estudiante actualización de sus esquemas de sentido común. Se actualizan por ejemplo las percepciones previas, los imaginarios, los supuestos acerca de la institución educativa sobre la que ahora reflexionan. La escuela normal poco a poco se constituye en una realidad pedagógica eminente, es decir, en una esfera del mundo social y cultural general que es común, circundante y comunicativo cuyos sujetos, procesos y objetos, son dados no solo a la experiencia de los estudiantes, también a sus idealizaciones y a sus imágenes de la educación y de la profesión docente.

Con ese acervo de conocimiento a la mano, reconstruyen sus primeras experiencias y reflexionan acerca de los primeros presupuestos. Sus reflexiones los conducen a algunos aspectos propios de la actitud natural específica de principiantes para quienes los objetos socioculturales de la escuela normal tendrían que tener un solo sentido, cumplir sus expectativas.

Berenice (E14adnslm, p. 8)por ejemplo, evidencia:

"... pensé que iba a ver muchas cosas de matemáticas, esperaba un curso. 
Nos habían dado el plan de estudios, [...] tenía en la cabeza que, como era una licenciatura en educación matemática, íbamos a estudiar un curso de álgebra, de geometría analítica, de cálculo, no sé, otra cosa. Pero en el primer año no vimos nada de matemáticas. Teníamos que conocer primero los propósitos de la educación secundaria. Yo decía, ¿porqué?, ¿para qué?, ¿y las matemáticas?, ¿dónde están?"

Las concepciones sociales heredadas son puestas de manifiesto, "pensé que iba a ver muchas cosas de matemáticas." Por supuesto, si la licenciatura por la que se opta es licenciatura en educación secundaria con especialidad en matemáticas, la conciencia de Berenice sólo enfoca "matemáticas" y espera estudiarlas de principio a fin. Sus anticipaciones, sus referentes, sus proyectos de vida entran en juego. Los sujetos y sus acciones, los materiales que encuentra en el círculo concéntrico de su actividad estudiantil poco a poco pasan de ser elementos incuestionados a elementos cuestionados de ese mundo.

La tematización de la escuela normal y sus objetos es otro de los procesos que ocurren en las etapas iniciales de la adquisición del conocimiento. Adyae (E01alsjlm, p. 7) explica:

”... Yo pensé que aquí esto iba a ser más específico, me decía, ¿matemáticas? desde el primer semestre, pero no, matemáticas las vimos hasta el tercer semestre y cosas así, bien fáciles. Sentía como que no estaba yendo a algún lado. [...] pensé que aquí me iban a enseñar, en primer lugar matemáticas, y en segundo, a enseñar matemáticas y lo primero que a uno le dicen es que, aquí te vamos a enseñar a enseñar matemáticas, no te vamos a enseñar matemáticas. Si sabes matemáticas qué bueno y si no, estúdiale por tu lado. Entonces yo preguntaba ¿por qué? si es licenciatura en matemáticas."

En el examen autorreflexivo que hace de este aspecto Andrea (E03linslm, p, 6 y 7) llega a similares referencias, y dice:

“... Al ingresar decía, me van a enseñar matemáticas. Yo traía de la universidad habilidades más fuertes, ahí había pasado un trimestre. [...] Por lo tanto, tenía habilidades más desarrolladas que el resto de mis compañeros de la normal superior o que algunos, porque otros también habían estudiado en la universidad. [...] Cuando llego aquí en el primer año, mis maestros fueron unos buenazos. Pero al otro año se relajó mucho el trabajo. Nos dieron desarrollo de los adolescentes, teníamos que ver los cambios físicos y biológicos de los adolescentes, pero no nos enseñaron nada de eso, no pasábamos de las patologías, que el narcisismo y que el yoyismo, y eso. Me decepcionó mi primer curso. [...] Hasta que llegamos más o menos al quinto semestre."

También Antonio (E06minslm, p. 5)expresa en el mismo tenor:

“... en los dos primeros semestres no tuvimos nada de matemáticas, $y$ no sé cómo pudimos pasar el primer semestre. Al menos yo no sé cómo pude pasarlo sin una sola materia de matemáticas. O sea, todo lo que yo veía aquí no era necesario para enseñar matemáticas, era pura historia de la pedagogía y norma de las escuelas secundarias. Fue algo así como una decepción cuando entré aquí. Después lo fui superando y hasta llegar 
hasta cuarto grado y más por las visitas que hacíamos a las escuelas. Esas experiencias que nos dejaban las prácticas en varias escuelas secundarias nos sirvieron. La experiencia que nos dejaban esas visitas a las escuelas era lo que nos impulsaba a seguir y decir que sí, que esto es lo que me gustaría hacer. Eso fue."

Todos los elementos anteriores, y otros que la investigación arroja, nos hacen pensar que las experiencias inmediatas de los estudiantes, en atención a los proyectos y esquemas de motivaciones pragmáticas que persiguen, se oponen a sus primeras percepciones de la Escuela Normal Superior. También se oponen, en cierta medida, a las tipificaciones que les fueron transferidas socialmente. La concordancia entre los componentes de su acervo de conocimiento se hace borrosa, deficiente, y hasta cierto punto, decepcionante. Mariana (E15arnslm, p. 4)define así la situación inicial de un estudiante en proceso de formación profesional en la institución educativa del caso:

"... pensé que aquí se nos iba poder brindar todas las asignaturas de inglés como enseñanza, pero fue una pequeña decepción, ya que dentro de la especialidad solamente se nos brindó, los dos primeros años, la metodología de cómo poder enseñar el inglés. [...] nosotros queríamos aprender cosas nuevas y no solamente el cómo poder enseñar ¿no?, para nosotros era más indispensable poder manejar el idioma, el ingles en este caso."

La presunta validez de los esquemas socialmente transmitidos acerca de los estudios profesionales en la escuela de refe- rencia, queda suspendida hasta el quinto semestre, momento de la formación donde ocurre el encuentro con los contenidos de la especialidad tan largamente deseados. Los presupuestos elaborados como aspirantes y después como estudiantes son ahora cuestionables, la formación cae en la incertidumbre, deviene la formación cuestionada. En términos de esta atención a la vida, la duración de la carrera profesional es menor a lo que parece. Parece ser, que son cuatro los semestres que ocupan la conciencia del estudiante de formación inicial y son aquellos donde precisamente "encuentran" los contenidos por los cuales optaron inicialmente.

Poco a poco, y en atención a las novedades de cada experiencia vivida, el horizonte de la escuela normal superior todavía indeterminado para el estudiante de nuevo ingreso, presenta nuevas facetas. La familiarización con las personas y los objetos socioculturales va en aumento. Lo incuestionado se hace cuestionable. El acervo de conocimiento que se va ampliando, sirve como factor de solución de problemas que el estudiante enfrenta en la comprensión de las pautas pedagógicas establecidas en el ámbito escolar de referencia.

Ya familiarizados con la pauta sociocultural de la institución educativa, los alumnos entrevistados manifiestan experimentar su vida de estudiantes hasta cierto punto monótona. El cumplimiento de tareas, los horarios de clase, la revisión de textos, la consulta en biblioteca, entre otras, son actividades realizadas cotidianamente. Carlos y Rosa manifiestan: Carlos (E08osnslm, p. 7): 
“... Creo que no estaba acostumbrado a aprender en la forma como se aprende en la Normal, que se da un punto de vista analítico y reflexivo. Yo estaba acostumbrado a aprender como en medicina, como en la prepa, de manera memorística. Me dieron una lectura, la primera que me dieron en la Normal, me dicen: para mañana quiero un comentario de esa, yo me la aprendí como en medicina, y al otro día dice el maestro, ¿quién sabe de eso? y yo, pues, la repetí de memoria. Entonces, cuando me dicen que aquí no es así, que aquí basta con que digas esto, dije ¡qué fácil!, y cuando vi que no era tan fácil, pero como que reflexiónale, como que da tu punto de vista, entonces, ese fue, creo, uno de los conflictos, un problema, el que no sabía dar puntos de vista y reflexionar, sino sólo sabía repetirlo."

Rosa (E11sinslm, p. 10):

“... no sé, tal vez el desconocimiento o el aspecto de tener otro tipo de sistema, por ejemplo, en la Universidad, de la preparatoria hacia la Normal. En la Universidad teníamos exámenes y nos íbamos cada quien. Yo, como estudiante, a lo mejor todo el semestre nos la íbamos llevando y no nos preocupaba realmente y al final cuando teníamos que presentar examen, pues ahí si, empezábamos a trabajar, a estudiar, a pedir asesorías y todo eso. Y, ya pasábamos el examen. Aquí, en la normal era diferente porque teníamos que hacer un trabajo continuo de lecturas, resúmenes, ensayos, reportes, y una de las dificultades era la trascripción, o sea, yo tengo muchas ideas, pero al momento de expresarlas en el papel es un poco difícil."

Expresado anteriormente que en los primeros semestres los alumnos se en- cuentran con asignaturas poco relevantes para su formación especializada y que esa situación les provoca desánimo y decepción inicial, al verse contrariadas sus ideas previas en torno a la licenciatura por la que han optado. La investigación indica también que en ese lapso temporal de su formación profesional, reacomodan su propio estilo de aprendizaje. Los estudiantes bajo estudio hacen conscientes los problemas respecto del análisis y la expresión de juicios sobre los materiales de aprendizaje y los procesos didácticos que se organizan en cada clase. Mireya (E09hanslm, p. 7) por ejemplo manifiesta:

“... Mi primer problema es que a mí no me gusta leer, entonces, el que aquí se den muchas lecturas a mí me costó mucho trabajo porque en primera, no tenía el hábito, segundo, no es lo mismo leer, por leer, o sea, teníamos que comprender. Entonces, para mí era muy difícil porque mis amigos o mis compañeros hablaban de cosas que yo decía ¿a poco eso dice la lectura?, entonces para mí fue muy, muy difícil porque yo no me acoplaba a las cosas."

Los alumnos entrevistados reproducen en cierto modo, una idea que se viene acumulando en toda su trayectoria académica como estudiantes respecto de la profesión docente. Si la licenciatura cursada anuncia especialidades en matemáticas o en inglés, entonces ¿porque no se estudia matemáticas o inglés?, ¿cuál es la razón de estudiar otras cosas que no sean de la especialidad?

La razón que puede justificar la característica del plan de estudios en vigor es muy débil o no está debidamente trabajado en el proceso de socialización. Al parecer no basta con que se les haya informado que en 
los primeros semestres tendrían que "estudiar y comprender los momentos relevantes del desarrollo histórico de la atención educativa dirigida a los adolescentes" o identificarse con la carrera profesional que ha elegido cursar. Hay alumnos que aceptan que la adquisición del conocimiento en la escuela normal superior obedeció a intencionalidades forjadas en otros ámbitos educativos.

Adyae (E01alnslm, p. 4) expresa: “... no me gustaba estar en la normal, yo vine a dar aquí por azares del destino, estaba en la facultad de ciencias, ahí tuve algunos problemas y decidí salirme, me vine para acá, pero el trabajo de una facultad, en una universidad, es totalmente diferente al de una normal. Yo venía muy acelerada y aquí encontré todo bien pasivo, creo que eso fue lo que provocó mi apatía dentro de la normal superior. Recuerdo que para sacarme un seis en la facultad tenía que leer una "Biblia" de biología, me refiero a un librote. De esas páginas, me tenía que aprender tres capítulos y máximo me sacaba un siete. Aquí, en la normal es muy fácil pasar, si tú haces los trabajos pasas y si no los haces, no pasas, pero no son trabajos como me los pedían en la facultad que casi, casi eran una tesis. Inclusive, tenían que tener el método científico, aquí lo quise hacer y me dijeron que no, que estaba mal, que se trataba de dar mi opinión y a mí se me hace más fácil plasmar mi opinión. [...] sentía esa gran diferencia en los contenidos, como que aquí, en la normal, manejan la temática, la metodología, principalmente la didáctica. Y yo me acuerdo que mis maestros universitarios llegaban y llenaban el pizarrón de cosas, pero aquí te lo explican paso por paso."
Para alumnos como Adyae, la escuela normal fue salida a experiencias negativas previas. Los procesos de familiarización en la escuela normal le trajeron recuerdos de situaciones problemáticas anteriores, como por ejemplo, los esquemas de referencia ya sedimentados acerca del estudio de una profesión. Así, la escuela normal superior y sus objetos socioculturales, pasaron siempre por el filtro de sus experiencias vividas en los límites de otro estrato del mundo social y cultural que no deseó haber abandonado.

Parece ser que las aspiraciones truncadas otorgan derecho de minimizar la calidad que tiene la formación profesional adquirida en la escuela normal. Aquí se trata de una profesión fácil, la difícil era la anterior, en la universidad. Esa situación refleja, en cierta medida, que la adquisición del conocimiento no es homogénea, es difusa y parece estar influida por las determinaciones de orden social y cultural. La expresión "plasmar mi opinión es más fácil que aprender de memoria tres capítulos" evoca prácticas pedagógicas con fines diferentes. Sin embargo en la visión pragmática de la estudiante ambos estratos del mundo son idénticos. Ella esperaría que lo que se hace en una institución, se haga en la otra y así sucesivamente. En la conciencia escolar cotidiana los universos simbólicos son homogéneos.

\subsection{La vivencia del presente: el aquí y el ahora de la formación}

En el proceso de rememoración de las experiencias más significativas en la trayectoria de la formación, el presente es la temporalidad desde la cual se orienta la 
conciencia para reconocer la situación y los alcances significativos de cada producto relacionado.

Aquí y ahora, los estudiantes entrevistados se interpretan como estudiantes situados en la plenitud de sus prácticas educativas con estudiantes de secundaria, y también en pleno proceso de elaboración de sus documentos para titulación. En relación con esa situación, se ven obligados a la búsqueda independiente del conocimiento, a su adquisición por diferentes vías, ya sea acudiendo a bibliotecas, consultando a sus maestros de asignatura o la Internet; Theresa (E02nonslm: 2007, p. 3)por ejemplo, señala:

“...venir a la normal implica volverse estudiante otra vez, acatar responsabilidades que en las prácticas también tienes que inculcar en los alumnos. Entonces se vuelve interesante porque uno adquiere la necesidad de ir a investigar en las bibliotecas, de cumplir con las tareas, de realizar trabajos extras en algunos momentos."

También, la reflexión acerca de lo que se ha vivenciado en una semana de clases, las interpretaciones respecto de las actividades que son realizadas de ordinario, nos aproximaron al conocimiento de las diversas facetas que adquiere la dinámica de una formación que ha salido de las aulas de la escuela normal y que ahora se extiende al horizonte de la experiencia cotidiana en la escuela secundaria. Carlos (E08osnslm: 2007, p. 3) manifiesta que cuando realiza sus jornadas de práctica docente, su vida de estudiante reúne experiencias duales, como profesor practicante y estudiante, $\mathrm{y}$ en cada horizonte de su vida cotidiana es exigido: “... entro a la escuela (secundaria) a las siete de la mañana, salgo a las doce del día, regreso a la normal, hago horas de biblioteca. Por la tarde, tengo que atender lo de planeación, mi ensayo y algunos documentos extra."

Delia (E10ibnslm: 2007, p. 4) parece coincidir con Carlos cuando refiere que en el último periodo de la formación la dinámica se hace más compleja:

“... Mi vida de estudiante es cumplir con los trabajos propuestos al principio del semestre y bueno, la parte más importante de estos momentos es la adjuntía que tenemos en las escuelas secundarias. Básicamente es la escuela secundaria, los alumnos, los tutores y el trabajo con los asesores. También Mireya (E09hanslm: 2007, p. 2), explica algo similar: “... ahorita que estamos con los proyectos, nos revisan eso, después, tenemos que llegar a corregirlos, a hacer tareas, buscar libros, a buscar otras tesis, volver a regresar a platicar con nuestro asesor para ver qué opina.

Exigidos durante el último trecho de su formación, los estudiantes de la ENSEM se ocupan en diferentes actividades: asisten a las escuelas de práctica, platican con los asesores, revisan sus planes, elaboran materiales. También se esfuerzan por diseñar sus propias estrategias didácticas o descubrirlas mediante la consulta bibliográfica o la entrevista con colegas. Se disponen a apropiarse por sus propios medios de los contenidos de sus materias, para poderlos trabajar con sus alumnos de práctica.

La adquisición de la profesión docente no se aleja de las formas en que cada estudiante del caso, interpreta sus situacio- 
nes vividas en cada periodo de formación, en especial, los últimos semestres. Aquí va configurándose una especie de aprendizaje docente, en el cual, la intensidad de sus acciones escolares, se colige con las pulsiones activas por conocer y hacer cada vez más cosas, de avanzar en el dominio de los contenidos de su carrera, y avanzar aún más en el desarrollo de sus capacidades docentes.

El aprendizaje docente poco a poco se evidencia como un proceso que refleja el interés, la intencionalidad consciente por aprender a ser maestro, por no perder de vista el fin al que está ligada toda actividad escolar que se emprende. $Y$ es en atención a esos intereses cognoscitivos que los estudiantes explican lo que consideran como lo más relevante de su formación, como por ejemplo, el aprendizaje en las asignaturas relacionadas con la especialidad que han elegido o las prácticas docentes con estudiantes de secundaria.

El desempeño frente al grupo de práctica es crucial para los propósitos de formación, ahí se muestran inclusive, los errores en la planeación, en el manejo de los contenidos o en la forma de ejercer control sobre el grupo, situaciones pedagógicas que entre otras cosas obligan al estudiante a prestar atención a aspectos de su formación que hasta entonces no habían sido problemáticas. En este sentido son relevantes: “... las formas de enseñanza, las formas de manejar el grupo de dos maestras, sus formas de trabajar los contenidos, sus formas de hacerte llegar las cosas. Esas formas de enseñanza me han motivado para aprender" Adyae (E01alnslm: 2007, p. 11) o bien, “... la conciencia que he tomado en la idea de ser profesor [...] me he sensibilizado para el estudio de las matemáticas y para compartir eso con los estudiantes."Roberto (E04alfnslm: 2007, p. 12)

Estos elementos simbólicos, también evidencian la importancia del aprendizaje docente, que es de diverso orden y en ese sentido, complejo, porque sintetiza la teoría y la práctica de docencia y asimila intereses de orden diferente al realizar tareas propias de un alumno y en otro contexto exigir actividades de aprendizaje muy típicas entre los docentes. Aprender a planear las actividades docentes, como la clase, la incorporación del grupo de alumnos de secundaria a las actividades escolares planeadas; sumadas al estudio del adolescente y la observación del entorno escolar o la selección de las mejores estrategias de evaluación, son conocimientos, entre otros que no pueden ser concebidos como exclusivamente pedagógicos, disciplinarios o didácticos.

El aprendizaje docente tiene así su propia dinámica, se mueve entre el conocimiento de contenidos escolares típicos de la disciplina escolar de que se trate, matemáticas o inglés, en este caso, y al mismo tiempo se mueve entre el conocimiento y dominio de elementos pedagógicos para elaborar procesos, materiales y/o estrategias de enseñanza o de aprendizaje y evaluación. La complejidad de este tipo de aprendizaje que vale la pena seguir estudiando, llega a tal grado de significación en la vida cotidiana de cada sujeto, que éste lo ordena jerárquicamente, hasta conformarlo como parte de su acervo de conocimiento de la vida, de la educación, de los alumnos, de los maestros. Acervo de conocimiento siempre 
al alcance más o menos permanente de su manipulación, sobre todo para el momento de las prácticas docentes, donde es posible rememorar acciones y sucesos semejantes.

\section{Conclusiones}

Aproximarnos mediante los actos de interrogación a los aspectos significativos de la adquisición de la profesión docente, nos permitió entender en cierto modo, aunque todavía muy superficialmente, la manera como se constituye el propio Yo. Como un proceso continuo y discontinuo de planes y logros, de planes y fracasos. $O$ de planes, fracasos en la discontinuidad y recuperación de planes previos. O bien de planes, fracasos, discontinuidad y elaboración de nuevos fantaseos.

Circunstancias todas, que nos indican la interesante complejidad de la constitución sociocultural del Yo individual y social de cada estudiante, a través de un diferente pero convergente proceso de aprendizaje muy típico de la institución normalista. Mismo que nos permitió rechazar la idea de que la formación docente puede ser como cualquier otra profesión o que cualquiera puede ser profesor con tan solo saber leer y escribir. Por el contrario, la adquisición de la profesión docente, implica una dinámica cognoscitiva que enlaza experiencias típicamente docentes, es decir, que vinculan al mismo tiempo saberes y experiencias de orden pedagógico y disciplinario en el mundo de la vida escolar. Saberes que trascienden al contenido curricular de la enseñanza que los estudiantes normalistas realizan en las escuelas secundarias. Pero también saberes que por necesidad de la práctica escolar son eslabonados a procesos asistemáticos de actualización e inclusive de transformación de la educación y la profesión docente.

Los aprendizajes de maestro de los estudiantes normalistas suceden en el aula, en donde se hace latente la heterogeneidad de los grupos, la diferencia individual de los estudiantes de secundaria y para quienes el estudiante de la ENSEM tiene que organizar una serie de actividades a través de sus planes de clase.

La acomodación de sus saberes, sus referentes previos, la socialización de sus conocimientos, la toma de decisiones son elementos que irán caracterizando la etapa inicial de la profesionalización docente de los estudiantes de la normal.

\section{Nota}

De las entrevistas citadas: A cada una se le asignó una clave de identificación para preservar la identidad de los entrevistados. Un ejemplo de las claves utilizadas es: e14adnslm, donde e = entrevista; 14 = número de una lista que ocupa la persona entrevistada; $\mathrm{ad}=$ primeras dos letras de un nombre dado a la persona informante; $\mathrm{ns}=$ normal superior, $\mathrm{y} \mathrm{lm}=$ iniciales del entrevistador. 2007, refiere el año de su aplicación.

\section{Referencias}

Aguado, E. (1995) Educación y Pobreza (de la desigualdad social a la equidad). México: El Colegio Mexiquense.

Ausubel, D. P., Novack J. D., y Henesian, H. (1983). Psicología educativa: un punto de vista cognoscitivo. Segunda edición. México: Trillas.

Balán, J. (1974). LasHistorias de vida en ciencias sociales; Teoría y técnica. Buenos Aires: Ediciones Nueva Visión.

Berger, P., Luckmann, T. (1998). La construcción social de la realidad. Buenos Aires.

Carrizales, C. (1987). Los conceptos estelares en la formación, México: Universidad.

Cicourel, A.V. (1982). El método y la medida en sociología. Madrid: Editora Nacional.

Cohen, L. y Manion, L. (1990). Métodos de investigación 
educativa. Madrid: La Muralla.

Corenstein. Z. M., y Medina, M. P. (1997). Curso introductorio sobre historias y relatos de vida ciudadana, aproximaciones metodológicas y analíticas. Retos, procesos y sentidos, México: Centro de Estudios Educativos A. C./ Alianza Cívica, A. C.

De Ibarrola, M. (2003).Reflexiones sobre una propuesta integral para conocer la investigación educativa nacional. En Weiss, Eduardo, et. al. La Investigación Educativa en México, 1993-2001. México: COMIE.

De Landsheere, G. (1998). La investigación educativa en el mundo. México: FCE.

Dewey, J. (1998). Cómo pensamos. Barcelona: Paidós.

Durán, R. T. (2002). "Pedagogía como ciencia social". Revista Paedagogium, No. 9, enero-febrero. México.

Ferrari, M. (2011). Reconstruir la deconstrucción. http://www.jacquesderrida.com.ar/comentarios/ferraris_reconstruir_decontruccion.htm. Consultado en septiembre de 2012.

Guevara Niebla, G. (1991). “México ¿Un país de reprobados?”. Revista Nexos.

Guevara Niebla, G. (1992) La catástrofe silenciosa, México: FCE.

Ianni, O. (1998). Teorías de la globalización. CEIICHUNAM:Siglo XXI Editores.

Luckmann, T. (1996). Teoría de la acción social. Barcelona: Paidós.
Magrassi, G. (1979). La historia de vida. Buenos Aires: Centro Editor de América Latina, La nueva Biblioteca.

Menéndez, L. (2002).La teoría de la realidad social de Alfred Schutz, su lenta configuración. No. 9, enerofebrero. México: Revista Paedagogium.

Muñoz Izquierdo, C. y Ulloa,M. (2011). “Últimos en la prueba PISA”. México: Revista Nexos.

Pujadas, J. J. (1992). El método biográfico: el uso de las historias de vida en ciencias sociales. Madrid: Centro de Investigaciones Sociológicas.

Ricoeur, P. (1996). Sí mismo como Otro. Madrid: Siglo XXI.

Schutz A. y Luckmann. T. (2001). Las estructuras del mundo de la vida. Buenos Aires: Amorrortu.

Schutz, A. (1974). Estudios sobre teoría social. Buenos Aires: Amorrortu.

Schutz, A. (1993). Construcción significativa del mundo social. Barcelona: Paidós.

Schutz, A. (1995). El problema de la realidad social. Buenos Aires: Amorrortu.

Schwartz, H. y Jacobs, J. (1984) Sociología cualitativa. México,:Trillas.

Taylor S. y Bogdan, R. (1986) Introducción a los métodos de investigación. Buenos Aires: Paidós.

Villoro, L. (1982). Creer, saber, conocer. México: Siglo XXI Editores. 